\title{
Biossegurança e uso de equipamentos de proteção individual (EPI) na odontologia em tempos de Covid-19
}

\author{
- Mirilaini Lino Brancini Faculdade de Odontologia, Centro Universitário do Norte Paulista (Unorp), São José do Rio \\ Preto, SP, Brasil • Paula Renata de Souza Faculdade de Odontologia, Centro Universitário do Norte Paulista (Unorp), \\ São José do Rio Preto, SP, Brasil • Mayara Terenzi Faculdade de Odontologia, Centro Universitário do Norte Paulista \\ (Unorp), São José do Rio Preto, SP, Brasil • Taylane Soffener Berlanga de Araújo Faculdade de Odontologia, Centro \\ Universitário do Norte Paulista (Unorp), São José do Rio Preto, SP, Brasil • Andréa Candido dos Reis Departamento \\ de Materiais e Próteses Odontológicas, Faculdade de Odontologia de Ribeirão Preto, Universidade de São Paulo (USP), \\ Ribeirão Preto, Brasil
}

RESUMO || O coronavírus desafiou profissões e sistemas de saúde em todo mundo. O papel dos profissionais da odontologia na prevenção da transmissão da covid-19 é extremamente importante, pois eles estão expostos a aerossóis da cavidade oral de pacientes que podem conter vários microrganismos patogênicos. O atual momento proporcionou mudanças na odontologia, ocasionando uma alteração expressiva na forma de atendimento, na rotina e na utilização de equipamento de proteção individual (EPI) de forma adequada e segura dentro de um consultório odontológico. O objetivo deste artigo foi orientar o profissional sobre a biossegurança na odontologia e a importância do uso correto de EPI na prevenção de autoinfecção ou disseminação da covid-19 em épocas de pandemia. As bases de dados PubMed, LILACS, SciElo e Bireme serviram de pesquisas para os termos "infecções por coronavírus", "odontologia" e "biossegurança”. Os critérios de escolha dos artigos foram a forma de transmissão do novo coronavírus e as maneiras de prevenir a disseminação do vírus dentro do consultório odontológico publicados no período de 2004 até junho de 2020. Conclui-se que os profissionais de odontologia desempenham importante papel na prevenção da transmissão da covid-19 através de uso correto de EPI, do uso de agentes antimicrobianos na cavidade oral e do manejo adequado na triagem dos pacientes.

DESCRITORES | Covid-19; Equipamento de Proteção Individual; Odontologia.

ABSTRACT | Biosafety and use of EPI in dentistry in Covid-19 times • The corona virus (COVID-19) has challenged health professions and systems worldwide, the role of dental professionals in preventing the transmission of Covid-19 is extremely important, since they are exposed to aerosols in the oral cavity of patients that contain various microorganisms pathogenic. This current moment has brought changes in Dentistry, causing a significant change in the way of care, the routine and the use of PPE in an appropriate and safe way within a dental office. This article seeks to guide the professional on biosafety in dentistry and the importance of the correct use of PPE in the prevention of autoinfection or dissemination of Covid-19 in times of pandemic. The PubMed, LILACS, SciELO and Bireme databases served as a search for the terms changes by corona virus, dentistry and biosafety. The selection criteria were a form of transmission of the new Corona virus and ways of preventing the spread of the virus within the dental office, published between 2004 and June 2020. Dental professionals play an important role in preventing the transmission of Covid-19 by the correct use of PPE, use of antimicrobial agents in the oral cavity and proper management in screening patients. Guimarães, 94 CHF 12 Ribeirão Preto, SP, Brasil • 14094-550 E-mail: tsoffener3@gmail.com

- Received 11 Jan, 2021 • Accepted 01 Maio, 2021 


\section{INTRODUÇÃO}

A doença respiratória aguda causada pelo Severe Acute Respiratory Syndrome Coronavirus 2 (SARS-Cov-2) foi detectada pela primeira vez em Wuhan, Hubei, China. Sua transmissão pode ser pré-sintomática, ou seja, ela pode ocorrer até $48 \mathrm{~h}$ antes do início dos sintomas. É importante também reconhecer que o vírus se dissemina por meio de gotículas infecciosas, aerossóis ou pelo contato com superfícies contaminadas. ${ }^{1-3}$

O consultório odontológico pode ser considerado um local importante para disseminar o SARS-CoV-2 e os dentistas estão entre os profissionais de saúde que podem desenvolver essa síndrome respiratória. Além da tosse e da respiração do paciente infectado, dispositivos dentários, como peças de mão dentárias de alta velocidade, produzem uma grande quantidade de aerossol e gotículas, misturadas com a saliva ou, até mesmo, com sangue. ${ }^{2}$

Perante isto, muitos estudos demonstraram que as concentrações de aerossóis bacterianos e fúngicos aumentam durante as sessões de trabalho em consultórios odontológicos, especialmente em clínicas com várias cadeiras o que, portanto, aumenta a possibilidade de transmissão de agentes infecciosos. ${ }^{4}$ Lages et al. ${ }^{5}$ também concordam que as características da atividade do cirurgião-dentista, tais como o pequeno campo de visualização em que atua, os procedimentos invasivos que realiza e os instrumentos perfurocortantes de alta rotação e ultrassônicos que utilizam, assim como a proximidade física do paciente, condicionam a formação de aerossóis e respingos e favorecem a ocorrência de acidentes.

Assim sendo, cuidados específicos no que diz respeito ao cumprimento dos procedimentos de biossegurança são essenciais, fazendo-se necessário que toda a classe odontológica se conscientize de que durante o atendimento clínico devem ser realizadas técnicas assépticas, pois este ambiente é considerado de risco para a contaminação por covid-19. ${ }^{6}$

\section{OBJETIVO GERAL}

Atualizar a atual situação do risco de contágio da covid-19 em atendimentos odontológicos e apresentar de forma clara as normativas internacionais e nacionais que respaldam e dão suporte ao uso correto dos equipamentos de proteção individual (EPI).

\section{OBJETIVO ESPECÍFICO}

Orientar o profissional sobre biossegurança na odontologia e a importância do uso correto de EPI na prevenção de autoinfecção ou de disseminação da covid-19 em época de pandemia.

\section{MATERIAL E MÉTODO}

As bases de dados PubMed, LILACS, SciElo e Bireme serviram de instrumento de pesquisa para os termos "infecções por coronavírus", "odontologia" e "biossegurança". Os critérios de escolha foram a forma de transmissão do novo coronavírus e as maneiras de prevenir a disseminação do vírus dentro do consultório odontológico publicados no período de 2004 até junho de 2020. Além disso, houve consulta aos sites do Conselho Regional de Odontologia de São Paulo (CRO-SP), do Conselho Federal de Odontologia (CFO) e da Agência Nacional de Vigilância Sanitária (Anvisa) para apresentar as normativas mais importantes no contexto deste trabalho.

\section{DESENVOLVIMENTO \\ Odontologia e Covid-19}

A cirurgia oral é realizada usando uma variedade de ferramentas manuais, que incluem turbinas dentárias de alta velocidade, peças manuais micromotores, scalers ultrassônicos e seringas de água e ar. Eles produzem uma grande quantidade de partículas e respingos que podem conter microrganismos da cavidade oral dos pacientes, mas que não devem ser confundidos com a névoa (spray), o gotejamento e o espirro.7 Foi sugerido que esses aerossóis contenham bactérias e fungos, o que pode ser um fator de risco para infecção cruzada 
em profissionais de odontologia. As composições de bioaerossol são heterogêneas; eles podem conter sangue, microrganismos, células da mucosa, materiais restauradores, partículas dentárias, assim como grandes quantidades de saliva. Microrganismos patogênicos e micróbios das vias aéreas dos pacientes podem contaminar superfícies próximas e levar ao risco de contaminação por doenças associadas à transmissão de agentes infecciosos, como influenza, tuberculose, meningite ou síndromes respiratórias agudas graves. ${ }^{4}$

Micik et al.7 definiram o aerossol odontológico como partículas menores que 50 micrômetros. Esses agentes líquidos ou em solução podem permanecer por longo período como suspensão, dispersos no ar sob a forma de uma fina névoa de micropartículas que contaminam o ambiente e representam grande risco pela capacidade de penetrar e contaminar pacientes e profissionais através das vias respiratórias ou oculares.

Cuidados devem ser tomados para que não haja contaminação de um paciente para outro, uma vez que esses microrganismos podem ficar armazenados dentro da própria peça de mão, pois ocorre uma aspiração por alguns instantes ao pé do pedal dos aparelhos de alta rotação, mesmo que o instrumento rotatório esteja equipado com válvula antirretração. ${ }^{8}$

Meng et al. ${ }^{9}$ relatam que as observações atuais sugerem que pessoas de todas as idades são geralmente suscetíveis a essa nova doença infecciosa. No entanto, aqueles que estão em contato próximo com pacientes sintomáticos ou assintomáticos com covid-19, inclusive profissionais de saúde e outros pacientes no hospital, apresentam maior risco de infecção por SARS-CoV-2.

Montalli et al. ${ }^{10}$ afirmam que, nos procedimentos odontológicos, tanto a broca odontológica como a seringa para pulverização de água geram gotículas e aerossóis que se dispersam em todas as direções a uma distância superior a 2 metros, medida a partir do perímetro da cavidade oral.
Já Coulthard ${ }^{11}$ expões que até mesmo o jornal The New York Times lembrou ao mundo que a odontologia tinha o maior risco de contaminação por covid-19 do que outra qualquer profissão.

\section{Biossegurança e controle de infecção em ambiente odontológíco}

Meng et al. ${ }^{9}$ explicam que a higiene das mãos tem sido considerada a medida mais crítica para reduzir o risco de transmitir microrganismos aos pacientes. O SARS-CoV-2 pode persistir nas superfícies por algumas horas ou até por vários dias, dependendo do tipo de superfície, da temperatura ou da umidade do ambiente, o que reforça a necessidade de uma boa higiene das mãos e a importância de uma desinfecção completa de todas as superfícies da clínica odontológica.

Devido às características únicas dos procedimentos odontológicos, nos quais um grande número de gotículas e de aerossóis pode ser gerado, as medidas padrão de proteção no trabalho clínico diário não são eficazes o suficiente para impedir a disseminação da covid-19, especialmente quando os pacientes estão no período de incubação e não sabem que estão infectados ou quando optam por ocultar a infecção. ${ }^{9}$

Perante isso, recursos devem ser utilizados para reduzir as exposições a material biológico, como as precauções padrão que recomendam considerar todos os pacientes como potencialmente contaminados quando houver a possibilidade de contato com sangue e outras secreções. Dentre essas precauções se destacam: higiene das mãos, o uso de EPI (Figura 1), o manuseio, o transporte e o descarte corretos de artigos perfurocortantes e a imunização. ${ }^{5}$

Santos et al. ${ }^{12}$ explicam que, em alguns casos, os microrganismos superam as medidas de segurança adotadas, colocando em risco pacientes e profissionais. Isso geralmente ocorre como resultado de negligência profissional em relação à biossegurança, o que intensifica o ciclo de infecção cruzada no consultório odontológico. 


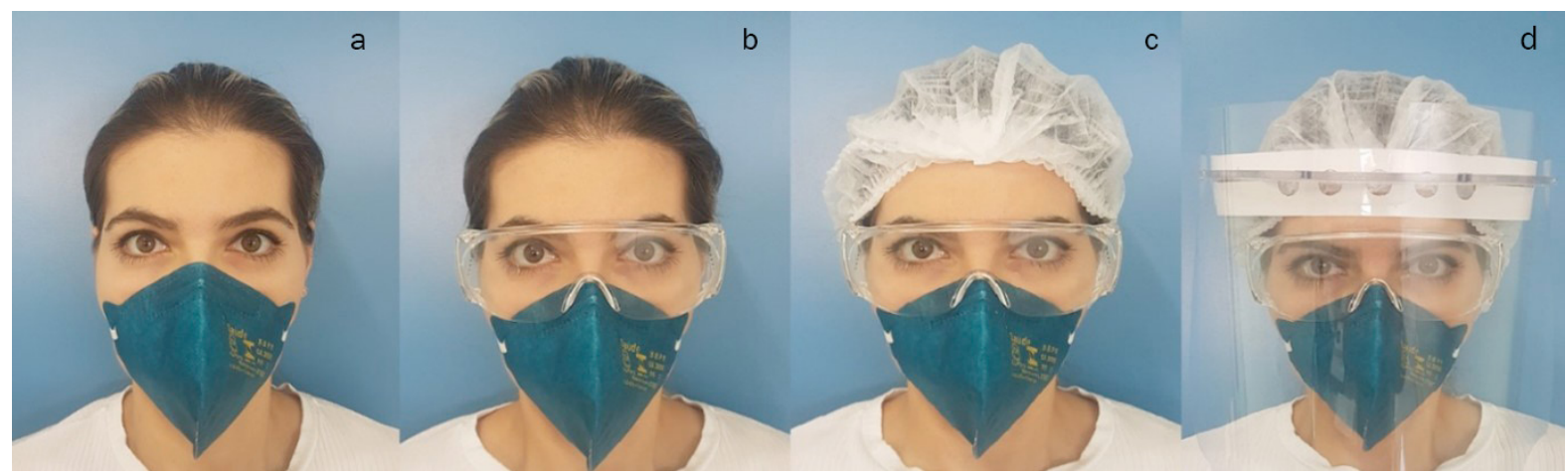

Figura 1 | Sequência de paramentação dos EPI. Figura 1a: colocação da máscara PFF-2; Figura 1b: colocação dos óculos de proteção; Figura 1c: colocação da touca; Figura 1d: colocação do protetor facial (faceshield). A desparamentação deve seguir a ordem inversa. ${ }^{1}$

Recomenda-se o uso de equipamentos de proteção individual, que incluem máscaras, luvas, avental, óculos e protetores faciais, para proteger tanto a pele como as mucosas do sangue ou de secreção potencialmente infectada (Figura 1). Como as gotículas respiratórias são a principal via de transmissão do SARS-CoV-2, os respiradores de partículas, por exemplo, máscaras N-95 autenticadas pelo Instituto Nacional de Segurança e Saúde Ocupacional ou máscaras padrão PFF-2 definidas pela União Europeia, são recomendadas para procedimentos odontológicos de rotina. ${ }^{9}$

Segundo o manual do CRO, os respiradores PFF-2 possuem 94\% de eficiência no bloqueio de aerossol e são equivalentes aos modelos N95, que apresentam eficiência de 95\% segundo a ABNT/NBR 13698:1996, ${ }^{13}$ e podem ser reutilizados enquanto estiverem em bom estado. Contudo, os respiradores devem ser protegidos com anteparos faciais para que não umedeçam e, assim, possam conferir proteção de até 4 horas. Quando úmidos, eles perdem sua efetividade de filtração e, por isso, não devem ser limpos ou desinfectados para reutilização, sendo, portanto, descartáveis. ${ }^{14}$

No entanto, outras medidas preventivas devem ser usadas por profissionais da área odontológica para reduzir os aerossóis, como o uso de uma solução de enxágue bucal pré procedimento com
0,12\% de clorexidina ou cloreto de cetilpiridínio a 0,05\% e a utilização de aspiradores de alto volume, muito eficazes para minimizar a contaminação por bioaerossol; já a combinação de ambos os métodos pode ser ainda mais eficaz. ${ }^{4}$

Santos et al. ${ }^{12}$ também concordam que o uso de agentes antimicrobianos pode ajudar a manter a integridade da estrutura dentária. A clorexidina é um agente químico com propriedades antimicrobianas capazes de inibir o crescimento bacteriano e de reduzir o número desses microrganismos na cavidade oral. Meng et al. ${ }^{9}$ também concordam que o enxágue bucal antimicrobiano pré-operatório pode reduzir o número de micróbios na cavidade oral.

Estudos emergentes reforçaram a importância da garganta e das glândulas salivares como locais de replicação e transmissão do vírus no início da covid-19. Sendo assim, pesquisas para reconhecer a eficácia dos enxaguantes bucais se fazem necessária na prevenção da transmissão. Em pesquisa recente, foi revisado o mecanismo de ruptura da membrana lipídica viral pelos componentes dos enxaguantes bucais amplamente utilizados bem como sua capacidade de interromper o envelope lipídico SARCoV-2, cuja conclusão foi que vários enxaguantes merecem avaliação clínica. ${ }^{6}$

Assim, um grupo de pesquisadores avaliaram a atividade virucida de diferentes soluções para 
bochechos disponíveis contra SARS-CoV-2 em condições que simulam secreções nasofaríngeas e concluíram que os enxaguantes bucais podem reduzir a carga viral da saliva. ${ }^{15}$

Ainda seguindo essa linha de pensamento, um centro de pesquisa e inovação com o apoio de quatro centros de pesquisa renomados de universidades brasileiras descobriram uma fórmula de antisséptico bucal capaz de inativar em 96\% a proliferação do vírus da covid-19. Essa eficácia foi comprovada com testes in vivo, tendo como base para este novo enxaguante a tecnologia Phtalox. ${ }^{16}$ Contudo, há uma grande preocupação por parte de alguns pesquisadores quanto aos efeitos adversos causados por estes produtos no seu uso a longo prazo, como as alterações na microbiota oral e nasal. Essas apreensões são demonstradas em revisão sistemática que afirma ter 16 estudos em andamento, sendo 14 ensaios clínicos randomizados, nos quais os pesquisadores afirmam que possíveis efeitos negativos não serão testados. ${ }^{17}$

Assim sendo, a Anvisa recomenta utilizar enxaguante bucal antimicrobiano pré-operatório no atendimento odontológico ${ }^{4}$ e os conselhos regulatórios recomendam aos cirurgiões dentistas que o bochecho seja realizado no lavabo, antes do paciente entrar na sala de atendimento. ${ }^{14,18}$

Os procedimentos que provavelmente induzem a tosse devem ser, se possível, evitados ou realizados com cautela e, do mesmo modo, os procedimentos de geração de aerossóis, como o uso de uma seringa de três vias, devem ser minimizados o máximo possível. Já o exame radiológico intraoral, técnica radiográfica mais comum em imagens dentárias, também pode estimular a secreção e a tosse. ${ }^{9}$ Por isso, a Anvisa recomenda o uso de radiografia extraorais e tomografias. ${ }^{3}$

Barragens de borracha e ejetores de saliva de alto volume podem ajudar a minimizar o aerossol ou os respingos em procedimentos odontológicos. Além disso, protetores faciais e óculos de proteção são essenciais durante o uso de perfuração com alta ou baixa rotação com jato de água. ${ }^{8}$ Quando o uso do isolamento não for possível de se realizar, preconizase a remoção de tecido cariados com gel próprio para este procedimento e a utilização de instrumentos manual, como escavadores dentinários ou curetas. ${ }^{3}$

Segundo Peng et al., ${ }^{19}$ atentos à possibilidade da propagação da infecção por 2019-nCoV, recomendam medidas de proteção para profissionais de odontologia em três níveis para situações específicas.

A proteção primária é a proteção padrão para equipe em condições clínicas e inclui vestir gorro descartável, máscara cirúrgica descartável e jalecos de trabalho e utilizar óculos de proteção e protetor de face que cubra a frente e os lados do rosto, equipamentos estes que são de utilização individual e que devem, após seu uso, ser limpos e desinfectados com fricção com álcool 70\% líquido por três vezes e com hipoclorito de sódio (1\%) (Figura 1). Além disso, esse nível de proteção inclui o uso de luvas descartáveis de látex ou vinil se necessário, mas sem haver a necessidade de utilizar duas luvas para atendimento dos pacientes, pois esta ação não garante mais segurança. Por fim, sempre se deve higienizar as mãos antes e imediatamente após a retirada das luvas. A proteção secundária, que é a proteção avançada para profissionais de odontologia, além dos procedimentos referidos na proteção primária, acrescenta o uso de jaleco descartável impermeável com gramatura mínima de $50 \mathrm{~g} / \mathrm{m}^{2} \mathrm{e}$ mangas longas com punho. O jaleco é descartável a cada uso e deve ser colocado por cima do avental cirúrgico. Já a proteção terciária é a proteção reforçada, necessária quando houver contato com paciente com suspeita ou confirmação de infecção por 2019-nCoV. ${ }^{19}$

Li et al. ${ }^{20}$ afirmam que, para minimizar a probabilidade de transmissão de doenças transmitidas pelo ar através de gotículas ou aerossóis, a equipe odontológica deve adotar os seguintes cuidados: a redução ou prevenção 
da geração de gotículas, o uso de isolamento de barragem de borracha, o uso de enxaguante bucal pré-procedimento, a diluição e remoção eficiente do ar ambiente contaminado, a desinfeção do ar e do aerossol gerado e a adoção de precaução de contato.

Os profissionais de odontologia há muito sabem que a diretriz básica para seu atendimento é ser o mais cauteloso possível, atendendo a todos os pacientes com o mesmo protocolo de biossegurança, admitindo que todos são "potencialmente contaminados", ${ }^{21}$ pois é de conhecimento do dentista o risco de infecção cruzada em seu ambiente de trabalho. Sendo assim, um detalhe por vezes esquecido é que, devido ao maior risco de contaminação, o cirurgião-dentista deve evitar levar o prontuário de seu paciente para dentro da sala de atendimento.

Os instrumentais odontológicos devem ser submetidos aos processos de desinfecção, lavagem e esterilização. A desinfecção do instrumental precisa ser realizada antes do processo de lavagem, com o intuito de diminuir o risco de infecção por parte daquele que fará a limpeza. ${ }^{22}$

Embora os cirurgiões-dentistas estejam classificados como um grupo de risco no contágio da covid-19, este grupo teve a menor contaminação desde o início da pandemia que em 11 de março de 2020. ${ }^{23}$ Em uma pesquisa realizada com 2.810 pacientes tratados em três diferentes consultórios e avaliados por seis meses, durante o estudo nenhuma transmissão de covid-19 foi registrada nem para os profissionais de saúde odontológica nem para os pacientes, muito embora $69 \%$ dos pacientes tratados nos consultórios odontológicos estudados tivessem registro de uma ou mais comorbidade de alto risco relacionada à gravidade do acometimento pela covid-19. ${ }^{24}$

\section{Surgimento do novo coronavírus}

Os coronavírus pertencem à família dos Coronaviridae e à ordem dos Nidovirales, compreendendo um RNA de fita grande, única e positiva como seu genoma. Atualmente, há quatro gêneros de corona vírus: $\alpha-\mathrm{CoV}, \beta-\mathrm{CoV}, \gamma-\mathrm{CoV}$ e $\delta$-CoV. A maioria dos corona vírus pode causar doenças infecciosas em humanos e vertebrados. $\mathrm{O} \alpha-\mathrm{CoV}$ e o $\beta$-CoV infectam principalmente o trato respiratório e gastrointestinal assim como o sistema nervoso central de humanos e mamíferos, enquanto o $\gamma$-CoV e o $\delta$ - $\mathrm{CoV}$ infectam principalmente as aves. Geralmente, diversos membros dos coronavírus causam doença respiratória leve em humanos; entretanto o SARS-CoV e o coronavírus da síndrome respiratória do Oriente Médio (MERS-CoV, da sigla em inglês), investigados em 2002 e 2003 respectivamente, causaram doenças respiratórias severas fatais. ${ }^{3}$

Um surto de pneumonia atípica foi relatado no final de dezembro de 2019 em Wuhan, China. Um novo coronavírus humano $(\mathrm{HCoV})$ foi isolado nesses casos e identificado como um betacoronavírus, provisoriamente chamado de novo vírus corona de 2019 (2019-nCoV). Em 11 de fevereiro de 2020, o Comitê Internacional de Taxonomia de Vírus nomeou o vírus "síndrome respiratória aguda grave corona vírus 2" (SARS-CoV2) e a Organização Mundial de Saúde anunciou a doença coronavírus 2019 (covid-19). ${ }^{3}$

Considerando que o SARS-CoV-2 foi recentemente identificado na saliva de pacientes infectados, o surto da covid-19 é um lembrete de que os cirurgiões-dentistas devem se preocupar com a disseminação de doenças infecciosas respiratórias, principalmente em relação à formação de aerossóis durante o atendimento odontológico. ${ }^{1}$

\section{Manifestação clínica do Covid 19}

Segundo Meng et al., ${ }^{9}$ a maioria dos pacientes com covid-19 representa casos relativamente leves. De acordo com estudos recentes, os dados da proporção de casos graves entre todos os pacientes com covid-19 na China foi de cerca de $15 \%$ a $25 \% .^{2,9}$

O período de incubação do covid-19 foi estimado entre 5 e 6 dias em média, mas há evidências de que ele poderia ser de até 14 dias, duração comumente 
adotada no atual momento para a observação médica e a quarentena de pessoas potencialmente expostas. ${ }^{9}$

Até o momento, o curso clínico da doença é heterogêneo; uma parcela dos pacientes apresenta curso clínico assintomático, enquanto outra parcela evolui com quadro clínico classificado como leve, moderado ou severo, conforme a gravidade do comprometimento clínico. ${ }^{1}$

Dentre os principais sinais e sintomas, destacamse: febre, tosse seca, apatia, mialgia, perda parcial ou total do olfato (hiposmia/anosmia), alteração, diminuição ou perda total do paladar (disgeusia/ hipogeusia/ageusia), insuficiência renal e doença respiratória aguda com necessidade de ventilação mecânica invasiva. A perda do paladar e de olfato são considerados sinais prodrômicos e devem ser questionados na anamnese pelo cirurgião-dentista. ${ }^{1,9}$

Meng et al. ${ }^{9}$ relatam que entre os pacientes submetidos à tomografia computadorizada de tórax (TC), a maioria apresentou pneumonia bilateral, com opacidade em vidro fosco e sombras irregulares bilaterais como os padrões mais comuns.

\section{Transmissão respiratórila de Covidd-19}

Por se tratar de uma infecção respiratória, a diferenciação da via de transmissão por gotículas provenientes da fala, tosse ou espirro - que apresentam tamanho da partícula $>5 \mu \mathrm{m}$, atingem até $1 \mathrm{~m}$ de distância do paciente fonte e permanecem segundos no ar - deve ser diferenciada da transmissão por partículas aerossolizadas - que apresentam tamanho da partícula $<5 \mu \mathrm{m}$, podem atingir vários metros de distância do paciente fonte $\mathrm{e}$ permanecem horas no ar -, em especial para auxiliar o cirurgião-dentista na escolha adequada de EPI.1,17

Peng et al. ${ }^{19}$ também concordam que as rotas comuns de transmissão do novo coronavírus incluem a transmissão direta (por tosse, espirro e inalação de gotículas) e a transmissão de contato (por meio de contato com as membranas mucosas orais, nasais e oculares) (Figura 2).

É sabido que a letalidade pode ser afetada por fatores como o conhecimento sobre a doença, a capacidade diagnóstica instalada e a superlotação hospitalar. ${ }^{22}$ De acordo com os dados atuais, a taxa de mortalidade, isto é, as mortes acumuladas divididas por casos cumulativos da covid-19 é de $0,39 \%$ a 4,05\%, dependendo das diferentes regiões da China. Essa taxa é menor que a da SARS $(\approx 10 \%)$ e a da MERS ( $\pm 34 \%)$ e superior à da gripe sazonal (0,01\% a $0,17 \%)$, de acordo com dados de 2010 a $2017 .^{3}$

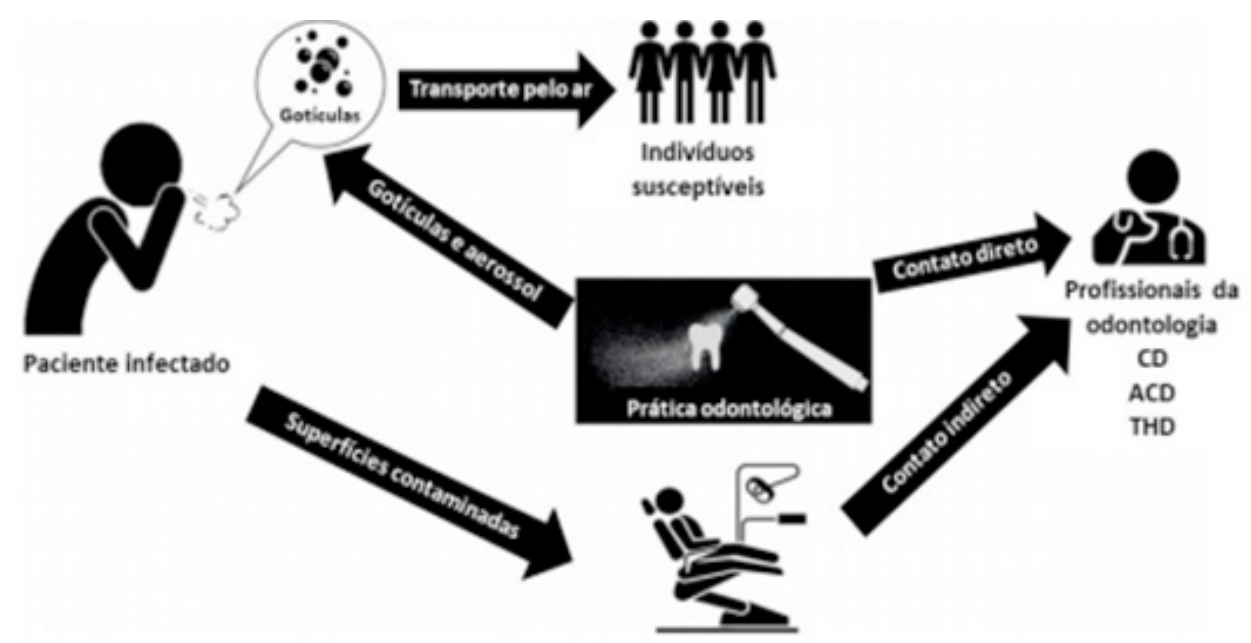

Figura 2 || Ilustração de rota de transmissão do covid-19 em práticas odontológicas

Fonte: Peng et al. ${ }^{19}$ 


\section{Modo de transmissão}

Com base em descobertas de pesquisas genéticas e epidemiológicas, parece que o surto de covid-19 começou com uma única transmissão de animal para humano, seguida de propagação sustentada de humano para humano. Acredita-se agora que sua transmissão interpessoal ocorra principalmente por meio de gotículas respiratórias e da transmissão de contato. Além disso, pode haver risco de transmissão fecal-oral, pois os pesquisadores identificaram o SARS-CoV-2 nas fezes de pacientes da China e dos Estados Unidos. ${ }^{2,8}$

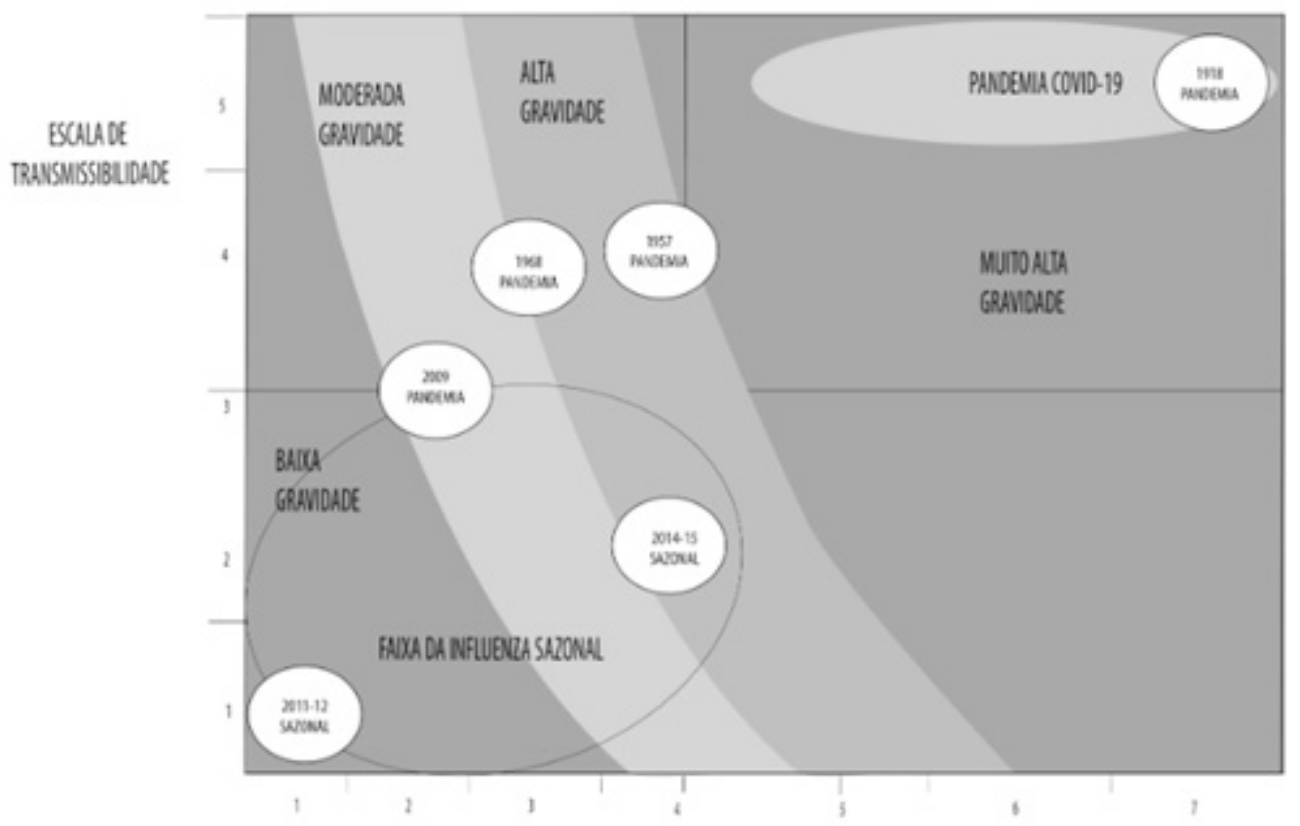

ESCLA DEGRMDADE

Figura 3 || Transmissibilidade e gravidade clínica da covid-19

Fonte: Freitas et al. ${ }^{21}$

Freitas et al. ${ }^{21}$ realizaram em sua pesquisa uma adaptação de um gráfico feito por Reed et al. ${ }^{24}$ ao analisarem a pandemia da influenza. Neste gráfico (Figura 3), pode se perceber os resultados das escalas de transmissibilidade e a gravidade clínica da covid-19, que se configura como uma doença altamente grave. Isso pode ser demonstrado por sua letalidade mundial e pelo fato de a epidemia já se encontrar na sua segunda onda em muitos países. ${ }^{25}$

\section{Fonte de transmissão}

Embora os pacientes sintomáticos com covid-19 tenham sido a principal fonte de transmissão, observações recentes sugerem que pacientes assintomáticos e pacientes em período de incubação também são portadores de SARS-CoV-2. Esse recurso epidemiológico da covid-19 torna seu controle extremamente desafiador, pois é difícil de se identificar os pacientes assintomáticos e de colocálos em quarentena a tempo de evitar a transmissão, dificuldades que podem resultar no acúmulo de SARS-CoV-2 nas comunidades. ${ }^{9}$

Spagnuolo et al. ${ }^{26}$ indica em estudo recente que o vírus pode sobreviver em superfícies de cobre e papel por mais de 24 horas, enquanto sua carga infecciosa drasticamente reduz-se somente após pelo menos 
48 horas em superfícies de aço e 72 horas nas de plástico. Portanto, o vírus permanece mais tempo em instrumentos de aço ou material descartável exposto aos fluxos de ar contaminado do que em uma revista na sala de espera, induzindo a importância de realizar higiene das mãos e das superfícies, uma vez que o vírus é completamente inativado por água, sabão e outros detergentes. Já, segundo Franco et al. ${ }^{1}$, o tempo de meia vida para o vírus em superfícies de plástico e de aço inoxidável é de 6,8 horas e 5,6 horas, respectivamente.

\section{Atendimento odontológico de pacientes com Covid-19}

Os pacientes que tossem, espirram ou recebem tratamento odontológico que inclua o uso de peça de mão de alta velocidade ou de instrumentos ultrassônicos têm suas secreções, sua saliva ou seu sangue aerossolizados nos arredores. O aparelho dentário pode ser contaminado com vários microrganismos patogênicos após o uso desses tratamentos, após a exposição a um ambiente clínico contaminado, por meio da punção de instrumentos cortantes ou do contato direto entre membranas mucosas e mãos contaminadas. ${ }^{9}$

Franco et al. ${ }^{1}$ informam que, segundo a American Dental Association (ADA), os procedimentos odontológicos a serem realizados pelo cirurgiãodentista em pacientes com covid-19 são:

\section{Emergências odlontológicas:}

São situações que apresentam risco de morte no atendimento odontológico: sangramentos não controlados; celulite ou infecções bacterianas difusas, com aumento de volume (edema) de localização intraoral ou extraoral e potencial risco de comprometimento da via aérea dos pacientes; e traumatismo envolvendo os ossos da face, com potencial comprometimento da via aérea do paciente. ${ }^{3,12,18}$

\section{Urgências odontológicas:}

São situações que denotam condições de prioridade no atendimento odontológico: dor odontológica aguda decorrente de inflamações da polpa dentária (pulpite); cárie extensa ou restaurações com problemas que causem dor; pericoronarite ou dor relacionada a processos infecciosos envolvendo os terceiros molares retidos; alveolite pós-operatória, com controle ou aplicação medicamentosa local; abscessos (dentário ou periodontal) ou infecção bacteriana que resulta em dor localizada e edema; fratura de dente que resulta em dor ou causa trauma do tecido mole bucal; cimentação ou fixação de coroas ou próteses fixas, caso a restauração provisória ou definitiva estiver solta, perdida, quebrada ou estiver causando dor e/ou inflamação gengival; ajuste ou reparo de próteses removíveis que estejam causando dor ou que comprometam a função mastigatória; troca para medicação intracanal, para endodontia, caso o paciente esteja com dor, necroses orais com dor ou secreção purulenta; ajuste, troca ou remoção do arco ou dispositivo ortodôntico que estiver ulcerando a mucosa bucal; e trauma dentário com avulsão ou luxação ${ }^{3}$.

Durante a pandemia de covid-19, recomenda-se que as clínicas odontológicas estabeleçam triagens de pré-verificação para medir e registrar a temperatura de cada equipe e paciente como um procedimento de rotina. Os funcionários da triagem devem fazer perguntas aos pacientes sobre o estado de saúde e o histórico de contatos ou viagens e pacientes com febre devem ser registrados e encaminhados para hospitais designados. ${ }^{9}$

\section{CONCLUSÃO}

O risco de transmissão de doenças infecciosas é um elemento integrante da prática de saúde oral, principalmente na atual época da pandemia de covid-19. A biossegurança fortalece a necessidade do 
uso de equipamentos de proteção individual (EPI), especialmente de óculos de proteção, respirador (N95 ou PFF-2), protetores faciais e aventais descartáveis, trocados a cada paciente. O uso de soluções orais antimicrobianas é indicado para reduzir a carga microbiana bem como sua propagação, tornandose prática indispensável dentro dos consultórios odontológicos.

\section{REFERÊNCIAS}

1. Franco JB, Camargo AR, Peres MPSM. Cuidados odontológicos na era do COVID-19: recomendações para procedimentos odontológicos e profissionais. Rev Assoc Paul Cir Dent. 2020;74(1):18-21.

2. Napimoga MH, Freitas ARR. Odontologia vs síndrome respiratória aguda grave coronavirus 2: como enfrentar esse inimigo. Rev Gauch Odontol. 2020;68:1-2. doi: 10.1590/1981863720200001120200034

3. Agência Nacional de Vigilância Sanitária (BR). Nota Técnica gvims/ggtes/Anvisa $n^{0}$ 04/2020 - 26/02/2021: orientações para serviços de saúde: medidas de prevenção e controle que devem ser adotadas durante a assistência aos casos suspeitos ou confirmados de infecção pelo novo coronavírus (SARS-CoV-2) [Internet]. Brasília; 2020 [cited 2021 Mar 18]. Available from: https://www.gov.br/anvisa/pt-br/centraisdeconteudo/publicacoes/servicosdesaude/notas-tecnicas/ nota-tecnica-gvims_ggtes_anvisa-04_2020-25-02-parao-site.pdf/view

4. Kobza J, Pastuszka JS, Bragoszewska E. Do exposures to aerosols pose a risk to dental professionals? Occup Med. 2018;68(7):454-8. doi: 10.1093/occmed/kqyo95.

5. Lages SMR, Santos AF, Silva FF Jr, Costa JG. Formação em odontologia: o papel das instituições de ensino na prevenção do acidente com exposição a material biológico. Cienc Trab. 2015;17(54):182-7. doi: 10.4067/So71824492015000300005 .

6. O’Donnell VB, Thomas D, Stanton R, Maillard JY, Murphy RC, Jones SA, et al. Potential Role of Oral Rinses Targeting the Viral Lipid Envelope in SARS-CoV-2 Infection. Function. 2020;1(1):zqaaoo2. doi: 10.1093/function/zqaaoo2.

7. Micik RE, Miller RL, Mazzarella MA, Ryge G. Studies on dental aerobiology. I. Bacterial aerosols generated during dental procedures. J Dent Res. 1969;48(1):49-56. doi: 10.1177/00220345690480012401.
8. Harrel SK, Molinari J. Aerosols and splatter in dentistry: a brief review of the literature and infection control implications. J Am Dent Assoc. 2004;135(4):429-37. doi: 10.14219/ jada.archive.2004.0207.

9. Meng L, Hua F, Bian Z. Coronavirus Disease 2019 (COVID-19): Emerging and Future Challenges for Dental and Oral Medicine. J Dent Res. 2020;99(5):481-7. doi: 10.1177/0022034520914246.

10. Montalli VAM, Garcez AS, Montalli GAM, França FMG, Suzuki SS, Mian LMT, et al. Individual biosafety barrier in dentistry: an alternative in times of covid-19: preliminary study. Rev Gauch Odontol. 2020;68:1-7. doi: 10.1590/1981863720200001820200088.

11. Coulthard P. Dentistry and coronavirus (COVID-19): moral decision-making. Br Dent J. 2020;228(7):503-5. doi: 10.1038/ s41415-020-1482-1.

12. Santos IRM, Moreira ACA, Costa MG, Barbosa MC. Effect of $0.12 \%$ chlorhexidine in reducing microorganisms found in aerosol used for dental prophylaxis of patients submitted to fixed orthodontic treatment. Dental Press J Orthod. 2014;19(3):95-101. doi: 10.1590/2176-9451.19-3.095-101.oar.

13. Associação Brasileira de Normas Técnicas. NBR 136981996 - Equipamentos de Proteção Respiratória. Rio de Janeiro; 2011.

14. Conselho Regional de Odontologia de São Paulo. CROSP atualiza manual de biossegurança para atendimento durante a pandemia [Internet]. São Paulo; 2020 [cited 2021 Mar 18]. Available from: http://www.crosp.org.br/noticia/ ver/4101-2107-crosp-atualiza-manual-de-biosseguranapara-atendimento-durante-a-pandemia.html

15. Meister TL, Brüggemann Y, Todt D, Conzelmann C, Müller JA, Groß R, et al. Virucidal Efficacy of Different Oral Rinses Against Severe Acute Respiratory Syndrome Coronavirus 2. J Infect Dis. 2020;222(8):1289-92. doi: 10.1093/infdis/jiaa471.

16. Bastos L. FOB: pesquisa aponta que antisséptico bucal reduz a gravidade da covid-19. JCNET.com.br [Internet]. 2020 [cited 2021 Mar 20];Geral. Available from: https://www.jcnet.com. $\mathrm{br} /$ noticias/geral/2020/11/742112-fob--pesquisa-apontaque-antisseptico-bucal-reduz-a-gravidade-da-covid-19.html

17. Burton MJ, Clarkson JE, Goulao B, Glenny AM, McBain AJ, Schilder AG, et al. Antimicrobial mouthwashes (gargling) and nasal sprays administered to patients with suspected or confirmed COVID-19 infection to improve patient outcomes and to protect healthcare workers treating them. Cochrane Database Syst Rev. 2020;16(9):CDo13627. doi: 10.1002/14651858. CD013627.pub2. 
18. Conselho Federal de Odontologia (BR). Odontologia: sempre bem protegida, para bem proteger [Internet]. Brasília; 2020 [cited 2021 Mar 18]. Available from: https://website.cfo.org.br/ebook-da-campanha-odontologia-sempre-bem-protegida-parabem-proteger-reforca-seguranca-de-pacientes-e-profissionais/.

19. Peng X, Xu X, Li Y, Cheng L, Zhou X, Ren B. Transmission routes of 2019-nCoV and controls in dental practice. Int $\mathrm{J}$ Oral Sci. 2020;19(12):9. doi: 10.1038/s41368-020-0075-9.

20 Li RWK, Leung KWC, Sun FCS, Samaranayake LP. Severe Acute Respiratory Syndrome (SARS) and the GDP. Part I: Epidemiology, virology, pathology and general health issues. Br Dent J. 2004;197(2):77-8o. doi: 10.1038/sj.bdj.4811469.

21. Freitas ARR, Napimoga M, Donalisio MR. Análise da gravidade da pandemia de Covid-19. Epidemiol Serv Saúde. 2020;29(2): e2020119. doi: 10.5123/s1679-49742020000200008.

22. Pimentel MJ, Batista Filho MMV, Santos JP, Rosa MRD. Biossegurança: comportamento dos alunos de odontologia em relação ao controle de infecção cruzada. Cad Saude Colet. 2012;20(4):525-32. doi: 10.1590/S1414-462X2012000400017. 23. Froum SH, Froum SJ. Incidence of COVID-19 Virus Transmission in Three Dental Offices: a 6-Month Retrospective Study. Int J Periodontics Restorative Dent. 2020;40:853-859. doi: $10.11607 /$ prd 5455 .

24. Reed C, Biggerstaff M, Finelli L, Koonin LM, Beauvais D, Uzicanin A, et al. Novel framework for assessing epidemiologic effects of influenza epidemics and pandemics. Emerg Infec Dis. 2013;19(1):85-91. doi: 10.3201/eid1901.120124.

25. World Health Organization. Coronavirus disease (COVID-19) outbreak [Internet]. Geneva; 2020 [cited 2020 Mar 3]. Available from: https://www.who.int/emergencies/diseases/novelcoronavirus-2019

26. Spagnuolo G, Vito D, Rengo S, Tatullo M. COVID-19 Outbreak: an Overview on Dentistry. Int J Environ Res Public Health. 2020;17(6):2094. doi: 103390/ijerph1706204. 